\title{
The role of general practitioners in the pre hospital setting, as experienced by emergency medicine technicians: a qualitative study
}

Magnus Hjortdahl ${ }^{1^{*}}$, Erik Zakariassen ${ }^{1,2,3}$ and Torben Wisborg ${ }^{4,5,6}$

\begin{abstract}
Background: Together with the ambulances staffed with emergency medical technicians (EMTs), general practitioners (GPs) on call are the primary resources for handling emergencies outside hospitals in Norway. The benefit of the GP accompanying the ambulance to pre-hospital calls is a matter of controversy in Norway. The purpose of the present study was to gain better insight into the EMT's experiences with the role of the GPs in the care for critically ill patients in the pre-hospital setting.
\end{abstract}

Methods: We conducted four focus group interviews with EMTs at four different ambulance stations in Norway. Three of the stations were located at least 2 hours driving distance from the nearest hospital. The interviews were transcribed and analyzed using systematic text condensation.

Results: The EMTs described increasing confidence in emergency medicine during the last few years. However, they felt the need for GP participation in the ambulance when responding to a critically ill patient. The presence of GPS made the EMTs feel more confident, especially in unclear and difficult cases that did not fit into EMT guidelines. The main contributions of the GPs were described as diagnosis and decision-making. Bringing the physician to the patient shortened transportation time to the hospital and important medication could be started earlier. Several examples of sub-optimal treatment in the absence of the GP were given. The EMTs described discomfort with GPs not responding to the calls. They also experienced GPs responding to calls that did not function in the pre-hospital emergency setting. The EMTs reported a need for professional requirements for GPs taking part in out-of-hours work and mandatory interdisciplinary training on a regular basis.

Conclusions: EMTs want GPs to be present in challenging pre-hospital emergency settings. The presence of GPs is perceived as improving patient care. However, professional requirements are needed for GPs taking part in out-of-hours work, and the informants suggested a formalized area for training between EMTs and GPs on call.

Keywords: Chain of survival, Prehospital, General practitioner, Emergency medical technician, Rural

\section{Background}

When a person in Norway is in need of immediate medical care but not defined as having a life threatening situation, he has to consult the local emergency primary healthcare system (casualty clinics). These clinics are staffed by general practitioners (GPs) and organized by the municipalities. The GP will examine the patient, decide if treatment is needed, and if it is necessary

\footnotetext{
* Correspondence: magnus.hjortdahl@gmail.com

${ }^{1}$ National Centre for Emergency Primary Health Care, Uni Research Health, Bergen, Norway

Full list of author information is available at the end of the article
}

admit the patient to a hospital [1]. In rural areas, the nearest hospital may be several hours driving distance away.

If a life threatening situation is suspected, the public is advised to contact the regional national emergency communication center (EMCC) directly by calling the dedicated medical emergency number (113). The EMCC then classifies the problem using a decision making tool [2]. If the operator classifies the call as a life threatening situation ("red response"), an alarm is issued simultaneously to both the GP on call at the local casualty clinic and the local ambulance [2]. The intention is that 
the ambulance and the GP will attend to the patient as a team [3]. Training courses in emergency medicine for GPs working in a casualty clinic are available, but they are not mandatory. The ambulances are usually staffed with emergency medical technicians (EMTs) with 2 years of upper secondary school and 2 years apprenticeship training and certification as health personnel [3].

A national ambulance helicopter emergency medical service (HEMS) staffed with anesthesiologists is established throughout Norway. The HEMS is a limited resource and may be located a distance from the site of the emergency. The availability of the HEMS is also vulnerable to weather and competing missions [4]. A study of three Norwegian dispatch centers in 2007 found that the HEMS was alerted for approximately 8 percent of the "red responses" [5]. Therefore, pre-hospital emergency medicine in Norway is based on the local ambulance and GP on call, with the HEMS as an important supplement [3].

When there is a red response, the GP on call decides, at his or her own discretion, whether or not to accompany the ambulance. There are no official regulations concerning how the GP has to respond to a "red response". If the GP accompanies the ambulance, the local casualty clinic must manage without a physician until the GP returns. This may then lead to temporary weakening of local medical emergency readiness.

The benefit of GPs responding to these call outs is controversial in Norway. A study conducted in 2009 found that EMTs perceive themselves as more capable in emergency medicine than GPs. GPs were also described as the most problematic occupational group to cooperate with during emergencies [6]. Another study from 2009 found that pre-hospital involvement by casualty clinic GPs is important for optimal patient care [7]. Despite the recommendation by national committees that GPs should take part in these call outs [3], the GP is only alerted by the EMCC in 47\% of these incidents [5]. The frequency of alerting GPs vary between EMCCs, the cause of this is unknown.

To optimize the use of GPs as a resource in the chain of survival, we need information about EMTs' assessment of GP participation in prehospital patient care. The purpose of the present study was to gain better insight into the experiences of EMTs of the role of GPs in the care for critically ill patients in the pre-hospital setting.

\section{Methods}

\section{Data collection}

We conducted four focus group interviews with EMTs at four different ambulance stations in Norway. One focus group interview was performed at each station and tape recorded. One of the authors $(\mathrm{MH})$ conducted the interviews and one of the authors (EZ) observed the interviews to take notes and ask follow-up questions at the end of the interview. The interviewer $(\mathrm{MH})$ works as a GP and has part time work as a medical adviser to a local casualty clinic in his municipality. The observer (EZ) is a full time researcher $(\mathrm{PhD})$ in the field of emergency medicine with a background as an emergency medicine nurse. We used an interview guide that was discussed and adjusted after each interview. The participants were given oral and written information about the study prior to the interview.

\section{Participants}

The sampling strategy aimed at talking to EMTs working at ambulance stations located in rural areas. We invited four ambulance stations by email, and all stations accepted the invitation. Three of the stations were located at least 2 hours driving distance from the nearest hospital. All personnel working at the station were invited to participate. The interviews were conducted during the day time with a mix of on-duty and off-duty personnel. The number of participants ranged from five to nine, and their experience as EMTs ranged from under a year to over 10 years. Data sampling was terminated when saturation was reached, i.e. no new information occurred during interviews.

\section{Analysis}

The interviews were transcribed and analyzed using systematic text condensation as described by Malterud [8]. Initially, we read all of the material to obtain an overall impression. Next, we identified and sorted meaning units for the EMT experiences working with GPs in the pre-hospital setting. The units were then coded and the contents of each coded group condensed. Finally, we summarized the contents of each group into generalized descriptions of different aspects concerning the relationship between EMTs and GPs in this field.

\section{Approval}

The Regional Committees for Medical and Health Research Ethics (Health Region North) waived approval (e-mail dated 29.06.2012). The Data Protection Official for Research, Norwegian Social Science Data Services waived approval (letter dated 02.08.2012).

\section{Results}

\section{An important supplement}

The EMTs described an increased emphasis on training, guidelines, and protocols over the last few years, which has given them increased confidence in emergency medicine. However, EMTs still felt the need to have GPs accompany them when responding to critically ill patients. The presence of GPs made the EMTs feel more confident, especially in unclear and difficult cases that did not fit into their treatment guidelines. The more experienced EMTs were more likely to express the need for GPs. In contrast, 
one of the younger EMTs found it more interesting to treat the critically ill patients by himself, as long as everything went "by the book". On-call GPs were described by some as having more clinical skills and being better at diagnosing, especially when it came to children and psychiatric patients. The EMTs felt that the GPs have a greater repertoire of medications available. In most cases the EMTs expressed a desire to use the GP as a consultant when it came to diagnosing and decision making, allowing the EMTs to focus on practical skills. The EMTs reported that the GP was an important supplement to their skills.

EMT describing a call out to a seven months old boy with breathing problems and possible bronchiolitis, a condition the EMTs were not familiar with:

"The child was critically ill. I have never seen breathing like that before. Luckily, we had brought a doctor with us. It would have been catastrophic to the patient if the doctor didn't come along".

The GP's main contributions were described as deciding whether to admit a patient to the hospital and arranging for transportation to the hospital when needed. This contribution was especially important in the case of a patient living in a remote area. Means of transportation, such as ambulance airplanes and ambulance boats, are limited regional resources and, according to the EMTs, are only dispatched after the patient has been examined by a physician. The EMTs shared experience in which bringing the physician to the patient shortened transportation time to the hospital by several hours, and important medication could be started earlier. Reducing the distance traveled by the patient in the ambulance was also considered to be gentler on the patient.

"I remember when we responded to a 40-year-old woman with signs of a stroke. It took 55 minutes from the time that our alarm went off until she was with the neurosurgeon. In this case the GP accompanied us to the patient and he could start the process of transportation right away. If we would have had to transport her to a casualty clinic to see the GP first it would probably have taken two hours to reach the hospital. She is working as normal today".

\section{EMT}

\section{Suboptimal care}

The EMTs provided several examples of suboptimal treatment in the absence of the GP. The EMTs described situations in which they were forced to give treatment they were not formally given delegation to administer because no GP was present. In other examples, patients were not given the recommended pre-hospital treatment when the ambulance responded to patients without a GP. The EMTs also described discomfort with GPs not responding to the calls. The EMTs were forced to wait for the $\mathrm{GP}$, resulting in a delay in responding to the patient. On the other hand, the EMTs were understanding of the GPs' difficult task in prioritizing whether to leave the casualty clinic.

EMT when asked to comment on the GP's possibility to decide at her own discretion whether to respond to a call out:

\section{"Sometimes I believe that the GP just don't want to accompany us to the patient... Once we had to respond to a knife wound to the abdomen. The GP on call declined to come along. It was dreadful to respond to this patient without a doctor. This kind of incident is very rare to us, and the patient was in bad shape... It was also a challenge to administer further transportation while taking care of the patient being only to EMTs".}

\section{Dysfunctional GPs}

The EMTs also relayed experiences with GPs who responded but did not function well outside the office. The doctor then became a burden to the EMTs. This was thought to be caused by some GPs having little interest in or knowledge of emergency medicine and little insight into EMT training and protocols. In other cases the GP had poor communication skills or lacked knowledge of geography or local procedures.

EMT describing how the GP can be a burden:

"Once we responded to a cardiac arrest. We were accompanied by a substitute GP. He elbowed his way past us and started to do chest compressions, on the stomach. The result was vomit everywhere. We had to push him out of the way to take care of the patient".

\section{Perfecting cooperation}

The EMTs had several thoughts concerning the role of the accompanying GP: a physician should understand the overall situation, allocate assignments, and formulate a plan of action, thereby assuming the role of the leader; have interest in and knowledge of emergency medicine, not only in an office or hospital setting; have insight into EMT guidelines and procedures; and be open to the thoughts and recommendations of the EMTs. Some EMTs expressed a preference for a humble GP that is earnest concerning his or her limitations. The EMTs described it as a good learning experience when the GP sits down with them after treating a patient and explains why he chose to deviate from their guidelines when this occurs.

The EMTs thought that a GP should have to fulfill certain requirements in order to work with emergency 
medicine. They also spoke favorably of interdisciplinary training. The EMTs reported a need for mandatory interdisciplinary training on a regular basis to achieve better knowledge and insight. The EMTs believed that this would result in better teamwork, and that both GPs and EMTs would have more respect for each other's knowledge and capabilities, leading to better patient treatment. All of the stations we visited have experience with this type of training program. Most of these training programs lost their quality over time or have been discontinued according to the EMTs. The EMTs noted that it was usually the GPs who were already interested and skilled in emergency medicine that took part in these programs.

"It is a problem that we respond to a patient without knowing the qualifications of the GP accompanying us. Interdisciplinary training gives us a unique opportunity to get to know each other. We, EMTs, train. The GPS are welcome to join in on our training, but they seldom have the time or desire to do so".

\section{EMT}

\section{Discussion}

\section{Sample and preconceptions}

Our sampling strategy focused on EMTs working in rural areas with a long distance to the local hospital. Therefore, one should be careful when transferring these results to an urban setting. Because we asked for volunteers to participate in the interview, there is a possibility that we ended up interviewing personnel with a special interest in the field, selection bias. This gives information from a select group, and one must be aware of this when generalizing the findings, but using a select group of informants thought to have information of interest to the study is in accordance with the applied method of qualitative research [9]. After conducting the four interviews, we read through the transcripts and found relevant material sufficient for analysis. The later groups had many of the same experiences as the first groups, which led us to conclude the data collection after four groups.

As one of the authors ( $\mathrm{MH}$ ) works part time as an instructor in interdisciplinary training, there is a risk of bias in favor of this type of training. We were aware of this preconception and conscious to minimize the effect of this background while planning, interviewing, and interpreting the interviews. Because the EMTs were interviewed by a physician (MH), the EMTs may have felt that they were being tested. The participants may also have given a falsely positive description of the role of the GP to please the interviewer. To counteract this, the interviewer was conscious of not being seen as an authority. It was felt that the informants freely discussed both the limitations and strengths of themselves, as well as those of the GP, during interviews.

Does the GP have a role in the pre-hospital environment? The EMTs wanted the aid of the GP as a leader and a diagnostic supplement in difficult cases. They also said that they could manage many acute patients on their own. Confidence in emergency medicine was reported in an earlier study showing that EMTs perceive their profession as being best suited to care for pre-hospital patients with severe injury or disease [6]. This may contradict the reported need for GPs in our study. In the previous study the EMTs could only chose EMT or physician as the profession considered best at caring for emergency patients. One interpretation of this choice is that the EMTs consider themselves best at practical skills and treatment according to guidelines. A previous study found that GPs seldom do emergency medical procedures, arguing that the GPs are not ready to take on a greater role in pre-hospital treatment [10]. Our study indicates that GPs could contribute by helping with diagnoses in unclear cases, being leaders, and organizing patient care, supplementing the EMT's skills. Leadership is an important human factor in emergency medical teams, as found when assessing teamwork in hospital trauma teams [11]. We were surprised to learn that the absences of GPs may lead to suboptimal treatment. This strengthens the argument that the presence of the GP is needed.

There is international controversy about who can provide the best medical care for critically ill patients in the pre-hospital setting [12]. Research in this field has focused on whether a well-trained paramedic or emergency medical service (EMS) physician is the best provider of care in these situations. Timmermann argued that some critically ill patients benefit from the care provided by the EMS physician, supporting our findings [12]. Because EMTs and GPs, rather than paramedics and EMS physicians, are the common resource in Norway, one must be careful to use these results in the Norwegian context.

Even though GPs are recommended to have a part in pre-hospital care in Norway, we do not know if their presence improves the overall outcome for patients. Further investigations should look into whether the presence of a GP actually shortens the time until treatment is started and until the patient is at the correct destination for further treatment. Whether the presence of a physician improves overall outcomes for patients should also be assessed. As noted by Timmermann, such a study will be challenging to design and execute [12].

Given our findings, it is a paradox that there are EMCCs that seldom alerts GPs, and that GP participation is low [5]. The GPs in casualty clinics have different reasons for not responding to call outs. One reason might be that the GPs are often preoccupied with other patients. Several 
studies have found that the "red response" patients are seldom in a life threatening situation when first examined by the EMT or physician [13,14]. If it was possible to develop some more specific guidelines for when the EMCC alerts the doctor, this may improve the GP response rate and possibly increase precision in getting them to respond to the "right" cases.

Our informants all had experience with poor performing GPs. This was perceived to be the result of a lack of interest and knowledge in emergency medicine and little insight into EMT guidelines. No special requirements or mandatory training currently exist in Norway for GPs working in casualty clinics. Previous studies have shown that GPs may be exposed to several different emergency situations, but some of them rarely [14]. A paper from 2009 investigating emergency medicine in a rural community suggested mandatory training on a regular basis for GPs taking part in out-of-hours work, supporting the view of our informants [7]. The need for interdisciplinary training as described by the EMTs has also been found in previous studies $[6,15]$.

\section{Conclusion}

The EMTs interviewed in this study reported wanting a GP present in challenging pre-hospital emergency settings that go beyond their guidelines. The presence of GPs was perceived to improve patient care. The EMTs considered a need for professional requirements for GPs taking part in out-of-hours work. The informants suggested formal training between EMTs and GPs on call.

\section{Competing interests}

The authors declare that they have no competing interests.

\section{Authors' contributions}

MH, EZ and TW participated in study design, in data acquisition and analysis, and critically revised the draft manuscript. All authors read and approved the final manuscript.

\section{Acknowledgements}

Magnus Hjortdahl received founding from The Norwegian Committee on Research in General Practice. We are thankful to all EMTs that participated in this study.

\section{Author details \\ 'National Centre for Emergency Primary Health Care, Uni Research Health, Bergen, Norway. ${ }^{2}$ Department of Research, Norwegian Air Ambulance Foundation, Post box 94, 1441 Drøbak, Norway. ${ }^{3}$ Department of Global Public Health and Primary Care University of Bergen, Post box 7804, 5020 Bergen, Norway. ${ }^{4}$ Norwegian National Advisory Unit on Trauma, Division of Emergencies and Critical Care, Oslo University Hospital, Oslo, Norway. ${ }^{5}$ Anaesthesia and Critical Care Research Group, Faculty of Health Sciences, University of Tromsø, Tromsø, Norway. ${ }^{6}$ Department of Acute Care, Hammerfest hospital, Finnmark Hospital Trust, Hammerfest, Norway.}

Received: 6 March 2014 Accepted: 5 August 2014

Published: 22 August 2014

\section{References}

1. Norwegian Ministry og Helth and Care services: Forskrift om krav til akuttmedisinske tjenester utenfor sykehus. (Regulation on pre-hospital emergency medicine services). http://www.lovdata.no/for/sf/ho/xo-20050318-0252.html.
2. Norwegian Medical Association: Norsk indeks for Medisinsk Nødhjelp (Noregian Index for Medical Emergency Assistance). 3rd edition. Stavanger: Laerdal Medical A/S; 2009.

3. Rapport fra arbeidsgruppe nedsatt av RHFene, inkludert vurdering etter høringsrunde: Working Group Regional Health Authorities of Norway: Report on organization of treatment of seriously injured patients - Trauma system. Oslo: 2007. http://www.helse-nord.no/getfile.php/RHF\%20INTER/ Artikler_nyhetssaker/Traumesystem\%20endelig\%20rapport.pdf.

4. Haug B, Åvall A, Monsen S-A: Reliability of air ambulances - a survey in three municipalities in Helgeland. Tidskr Nor Legeforen 2009, 129:1089-1093.

5. Zakariassen E, Hunskaar S: Involvement in emergency situations by primary care doctors on-call in Norway-a prospective population-based observational study. BMC Emerg Med 2010, 10:5

6. Førland $\mathrm{O}$, Zakariassen $\mathrm{E}$, Hunskår S: Cooperation between ambulance personnel and regular general practitioners. Tidskr Nor Legeforen 2009, 129:1109-1111.

7. Rørtveit S, Hunskår S: Management of emergency medical events in a rural community. Tidskr Nor Legeforen 2009, 129:735-737.

8. Malterud K: Systematic text condensation: A strategy for qualitative analysis. Scan J Public Health 2012, 40:795-805.

9. Malterud K: Qualitative research: standards, challenges, and guidelines. Lancet 2001, 358:483-488.

10. Brattebø $\mathrm{G}$, Torben $\mathrm{W}$ : Confidence and experience in emergency medicine procedures. Norwegian general practitioners. Scand J Prim Health Care 2001, 19:99-100.

11. Hjortdahl M, Ringen AH, Naess AC, Wisborg T: Leadership is the essential non-technical skill in the trauma team - results of a qualitative study. Scand J Trauma Resusc Emerg Med 2009, 17:48.

12. Timmermann A, Russo SG, Hollmann MW: Paramedic versus emergency physician emergency medical service: role of the anaesthesiologist and the European versus the Anglo-American concept. Curr Opin Anesthesiol 2008, 21:222-227.

13. Zakariassen E, Burman RA, Hunskaar S: The epidemiology of medical emergency contacts outside hospitals in Norway-a prospective population based study. Scand J Trauma Resusc Emerg Med 2010, 18:9.

14. Rørtveit S, Hunskår S: Medical emergencies in a rural community. Tidskt Nor Legefor 2009, 129:738-742.

15. Zakariassen E, Sandvik H, Hunskaar S: Norwegian regular general practitioners' experiences with out-of-hours emergency situations and procedures. Emerg Med J 2008, 25:528-533.

doi:10.1186/s13049-014-0047-1

Cite this article as: Hjortdahl et al:: The role of general practitioners in the pre hospital setting, as experienced by emergency medicine technicians: a qualitative study. Scandinavian Journal of Trauma, Resuscitation and Emergency Medicine 2014 22:47.

\section{Submit your next manuscript to BioMed Central and take full advantage of:}

- Convenient online submission

- Thorough peer review

- No space constraints or color figure charges

- Immediate publication on acceptance

- Inclusion in PubMed, CAS, Scopus and Google Scholar

- Research which is freely available for redistribution 